\title{
MENOPAUSAL, DEPRESSIVE SYMPTOMS AND RELIGIOSITY AMONG WOMEN ATTENDING THE GYNAECOLOGY CLINIC IN A PUBLIC HOSPITAL
}

\author{
Rosida Jelani ${ }^{1,2}$ and Siti Khuzaimah Ahmad Sharoni ${ }^{1}$ \\ ${ }^{1}$ Centre for Nursing Studies, Faculty of Health Sciences, Universiti Teknologi MARA, Puncak Alam Campus, 42300 Puncak \\ Alam, Selangor, Malaysia. \\ ²Unit Penyeliaan Jururawat, Hospital Sungai Buloh, Jalan Hospital, 47000 Sungai Buloh, Selangor, Malaysia.
}

\section{Corresponding author: Siti Khuzaimah Ahmad Sharoni}

Email: sitik123@uitm.edu.my

\begin{abstract}
Menopause is a normal development in women's lives. Having depressive symptoms during the menopausal transition can be managed, and in many health conditions, religiosity may play an important role in reducing the severity. The objective of this study was to determine menopausal, depressive symptoms and religiosity among women attending the Gynaecology Clinic in a Public Hospital. A cross-sectional study was done at Hospital Sungai Buloh involving 232 women aged 40-60 years from January 2020 to March 2020. The Menopause Rating Scale (MRS), the Centre for Epidemiology Studies-Depression Scale-Revised (CESD-R), the Duke Religious Index (DUREL) and socio-demographic data were used as research tools in this study. The respondents were categorised as premenopausal ( $n=98,42.2 \%)$, perimenopausal $(n=81,34.9 \%)$ and postmenopausal $(n=53,22.8 \%)$. The highest percentage of menopausal symptoms were muscle discomfort (56.5\%), sleeping problems and lethargy (54.3\%). The prevalence of depressive symptoms was $19.2 \%$, and the results showed that unmarried women were more depressed compared to married women $(p<0.05)$. The

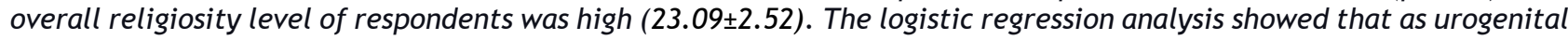
problems arise, their depressive symptoms will also increase $(p<0.05)$. Women who are transitioning to menopause should be assessed continuously for the severity of urogenital problems as it can impact their psychological and emotional well-being, and depressive symptoms should be assessed thoroughly especially among unmarried women.
\end{abstract}

Keywords: Menopausal, Depressive, Religiosity, Women

\section{INTRODUCTION}

Menopause is a typical condition that all women go through as they age. Menopause, described as the total cessation of the menstrual cycles, is generally correlated with the progressive loss of ovarian follicles. Natural menopause occurs after 12 consecutive months of amenorrhea for which no other physiological or pathological cause exists ${ }^{1}$. Menopause is an unavoidable aspect of ageing and entails the loss of reproductive ovarian function, which happens either naturally or due to other conditions, such as early menopause ${ }^{2}$.

The expression "menopause" is regularly used to represent any of the progression a woman encounters either just previously or after she quits bleeding, denoting the end of her regenerative period. Each lady will unexpectedly face menopause during her midlife years ${ }^{3}$. The menopausal advancement frequently begins in the mid ' $40 \mathrm{~s}$ and it is expected to be divided into a few stages. In a few women, the period of menopause may be at 51 or 52 years of age ${ }^{4}$. The most common symptoms among menopausal women are joint and muscular discomfort (73.3\%), followed by fatigue $(58.3 \%)^{5}$. Other physical changes during the transition to menopause and post-menopause are back pain, breast discomfort, nausea, night sweats, sleep disturbances, less interest in sex, and frequent urination, and sometimes loss of focus ${ }^{5}$. A previous local study reported that the average age for menopause was 52 years and the most common reported menopausal symptoms were joint and muscle soreness, and urinary tract conditions ${ }^{6}$.

Menopausal women commonly reported of having depressive symptoms. Gaining knowledge of the menopause symptoms helps to lessen the burden and stress associated with the condition ${ }^{7}$. The perimenopausal period could last up to six years ${ }^{8}$ and the risk of developing depression during perimenopause could be as high as 14 times more than premenopausal women ${ }^{5}$. Women in the middle ages and having menopause are detected as being vulnerable to many emotional related problems such as depression, anger, and anxiety ${ }^{9}$. Similarly, some studies identified that women experience a wide range of physical and psychological symptoms concerning menopause ${ }^{6}$ ${ }^{10}$. Thus, the aspect of emotional care is essential, especially among women who experienced a transition period of menopause, to allow and help them in identifying their condition and feelings, and learning to accept it.

Religion involves beliefs, practices and rituals related to the sacred. Religious commitment is defined as the degree to which a person adheres to their religious values, beliefs, and practices and uses them in daily living ${ }^{11}$. Religiosity has been operationalised and measured in several ways, including participation in religious 
organisations, the degree of participation in religious activities, the attitudes and importance of religious experience and belief in traditional religious creeds ${ }^{12}$. It was reported that those who had the most frequent and recent religious service attendance had the lowest risk of developing depression ${ }^{13}$. Therefore, this study was conducted to determine the menopausal, depressive symptoms and religiosity among women attending the Gynaecology Clinic in a Public Hospital.

\section{METHODS}

The design of this study is a quantitative method with a cross-sectional design, to guide the research in menopausal, depressive symptoms and its association with religiosity among women attending the gynaecology clinic in a public hospital. A three-month quantitative design study was conducted at the Sungai Buloh Hospital Gynaecology Clinic, Obstetrics and Gynaecology Department, from January 1, 2020, to March 31, 2020. The hospital service covers three districts where the community in these areas make up $40 \%$ of the total population in a state with approximately 2.18 million inhabitants and provides secondary and tertiary services.

The sample size calculation was determined as calculated by Raosoft software ${ }^{14}$ with a Margin of Error of 5\% and Confidence Level 95\%, as well as published data by Rahman et al. ${ }^{15}$ who reported that the prevalence of the most common menopausal symptoms was $80.1 \%$. The estimated sample size was $232(\mathrm{n}=232)$.

Data was collected within three months, between January and March 2020. Purposive sampling technique was used and the potential respondents, women attending the Gynaecology Clinic every Mondays and Fridays, who met all eligibility criteria were included in the study.

\section{Inclusion and Exclusion Criteria}

The eligibility criteria were all women age 40 years to 60 years, Malaysian citizens and were able to understand Malay or English. Women receiving Hormone Replacement Therapy (HRT) were excluded from the study.

\section{Instruments}

The instruments used were adopted from the Menopause Rating Scale (MRS) ${ }^{16}$, The Centre for Epidemiology Studies, that was revised in 2004 for the depressive symptoms (CESD-R) ${ }^{17}$ and the Duke University Religion Index (DUREL), where the Malay version was developed in 2010 by Nurasikin et al. ${ }^{18}$ to assess the religiosity.

A total of 43 questions were used and covered the eligible participants' socio-demographic data, menopause and depressive symptoms and the religiosity of the women. The instruments were divided into four sections. Section A is sociodemographic data which has seven items, Section $B$ is menopause symptoms comprising of 11 items, Section C is depressive symptoms (20 items) and Section D comprises of religious practice with five items.

The instrument was subject to peer review by research experts who ensured that the methodology was accurate when resolving ambiguities and concentrated on items that fulfilled the intended purpose of the analysis. A pilot study was done before the actual study was conducted and found that the Cronbach Alpha for the instruments were acceptable for MRS $(\alpha=0.80)$, CESD-R $(\alpha=0.75)$ and DUREL $(\alpha=0.69)$.

The data collected were analysed with IBM SPSS Statistics Version 23. The descriptive and inferential statistics (i.e. independent t-test, Chisquare and logistic regression) were used for the analysis and a $p$ value of less than 0.05 was considered significant, to reject the null hypothesis.

\section{Ethical Consideration}

Ethical approval was obtained from UiTM ethical committee (600-IRMI $(5 / 1 / 6)$ prior to the commencement of the study. The approval was also granted by the National Medical Research Registry (NMMR) 19-2914-51192 and by the Malaysian Research Ethics Committee (MREC) (KKM / NIHSEC / P19-2248(7). Permission was obtained from the Director of Sungai Buloh Hospital through a letter of reference Bil (182) HSB / CRC/770/21/01/07 Jld and, at the same time, from the Head of Obstetrics and Gynaecology and Psychiatrics Departments before data collection process began. Respondents were informed about the study matter and their confidentiality was maintained.

\section{RESULTS}

\section{Socio-demographic data of respondents}

As indicated in Table 1, a total of 232 women aged 40 - 60 years old were invited to participate in this study. All of them (100\%) completed the questionnaires. The average age of the women was $47( \pm 4.28)$ years. Most of the respondents were Malay, $(n=214,92.2 \%)$, tertiary level graduates $(n=98,42.2 \%)$, married $(n=225,97 \%)$ and $165(71.1 \%)$ of them were employed. Meanwhile, 115 (49.6\%) women were from the T20 group with an income of above RM9620. For the menstrual status, $98(42.2 \%)$ of them were premenopausal, followed by 81 (34.9\%) perimenopausal and $53(22.8 \%)$, menopausal. 
Table 1: Socio-demographic data $(n=232)$

\begin{tabular}{|c|c|c|}
\hline & Frequency & Percentage (\%) \\
\hline Age $($ Mean \pm SD) & \multicolumn{2}{|c|}{$47.32 \pm 4.28$} \\
\hline Ethnic & & \\
\hline Malay & 214 & 92.2 \\
\hline Non-Malay & 18 & 7.8 \\
\hline \multicolumn{3}{|l|}{ Educational Level } \\
\hline None & 17 & 7.3 \\
\hline Primary School & 65 & 28.1 \\
\hline Secondary School & 52 & 22.4 \\
\hline Tertiary Level & 98 & 42.2 \\
\hline \multicolumn{3}{|l|}{ Marital Status } \\
\hline Unmarried & 7 & 3 \\
\hline Married & 225 & 97 \\
\hline \multicolumn{3}{|l|}{ Occupational } \\
\hline Unemployed & 67 & 28.9 \\
\hline Employed & 165 & 71.1 \\
\hline Household Income $($ Mean \pm SD) & \multicolumn{2}{|c|}{$5197.9 \pm 4044.4$} \\
\hline B40 (Below RM4360.00) & 62 & 26.7 \\
\hline M40 (RM4361 - RM9619.00) & 55 & 23.7 \\
\hline T20 (Above RM9620.00) & 115 & 49.6 \\
\hline \multicolumn{3}{|l|}{ Menstrual Status } \\
\hline Premenopausal & 98 & 42.2 \\
\hline Perimenopausal & 81 & 34.9 \\
\hline Postmenopausal & 53 & 22.8 \\
\hline
\end{tabular}

Table 2: Menopausal symptoms $(n=232)$

\begin{tabular}{|c|c|c|c|c|c|}
\hline & NO & MILD & MODERATE & SEVERE & VERY SEVERE \\
\hline & n (\%) & $\mathrm{n}(\%)$ & n (\%) & $\mathrm{n}(\%)$ & $\mathrm{n}(\%)$ \\
\hline \multicolumn{6}{|l|}{ Somatic } \\
\hline $\begin{array}{l}\text { Joint and muscular } \\
\text { discomfort }\end{array}$ & $101(43.53)$ & $72(31.03)$ & $42(18.10)$ & $14(6.03)$ & $3(1.29)$ \\
\hline Sleep problems & $106(45.69)$ & $53(22.84)$ & $58(25.00)$ & $12(5.17)$ & $3(1.29)$ \\
\hline Hot flushes & $115(49.57)$ & $70(30.17)$ & $44(18.97)$ & $3(1.29)$ & $0(0.00)$ \\
\hline Heart discomfort & $149(64.22)$ & $51(21.98)$ & $30(12.93)$ & $2(0.86)$ & $0(0.00)$ \\
\hline \multicolumn{6}{|l|}{ Psychological } \\
\hline Lethargy & $106(45.69)$ & $62(26.72)$ & $56(24.14)$ & $8(3.45)$ & $0(0.00)$ \\
\hline Anxiety & $109(46.98)$ & $71(30.60)$ & $43(18.53)$ & $9(3.88)$ & $0(0.00)$ \\
\hline Anger/ irritability & $114(49.14)$ & $68(29.31)$ & $39(16.81)$ & $10(4.31)$ & $1(0.43)$ \\
\hline Depression & $122(52.59)$ & $58(25)$ & $45(19.4)$ & $7(3.02)$ & $0(0.00)$ \\
\hline \multicolumn{6}{|l|}{ Urogenital } \\
\hline Sexual problems & $128(55.17)$ & $47(20.26)$ & $44(18.97)$ & $13(5.60)$ & $0(0.00)$ \\
\hline Vaginal dryness & $146(62.93)$ & $50(21.55)$ & $25(10.78)$ & $11(4.74)$ & $0(0.00)$ \\
\hline Urinary problems & $151(65.09)$ & 37 (15.95) & 35 (15.09) & $7(3.02)$ & $2(0.86)$ \\
\hline
\end{tabular}

Table 3: Depressive symptoms $(n=232)$

\begin{tabular}{lcc}
\hline Category of depressive & Frequency & Percentage (\%) \\
\hline No depressive symptoms $\leq 15$ & 186 & 80.2 \\
Depressive symptoms $\geq 16$ & 46 & 19.8 \\
\hline
\end{tabular}




\section{Menopausal symptoms}

Table 2 shows the frequency of menopausal symptoms at various menopausal stages. The most prevalent menopausal symptoms for all women $(n=232)$ were mainly from the somatic subscale; joint and muscular discomfort $(n=131,56.5 \%)$, sleeping problems $(n=126,54.3 \%)$ and hot flushes $(n=117,50.4 \%)$. The typical somatic symptoms of menopause less experienced were heart discomfort $(n=83,35.8 \%)$. For the psychological subscale symptoms, the highest reported by the respondents were feeling lethargic $(n=126$, $54.3 \%)$, followed by anxiety $(n=123,53 \%)$, anger $(n=118,50.9 \%)$ and depression $(n=110,47.4 \%)$.
For the urogenital subscale, symptoms reported included sexual problems ( $n=104,44.8 \%)$, vaginal dryness $(n=86,37 \%)$ and urinary problems $(n=81$, $34.9 \%)$.

\section{Depressive Symptoms}

Table 3 indicates that almost $80 \%(n=186)$ of the respondents did not have severe depression that can be significantly included in the category of clinical depressive symptoms. However, there were 46 , (20\%) that needed extra care with their depression issues due to subthreshold depressive symptoms.

Table 4: Religiosity $(n=232)$

\begin{tabular}{|c|c|c|c|}
\hline & Frequency (n) & Percentage (\%) & Min/Max \\
\hline \multicolumn{4}{|l|}{ ORA } \\
\hline 1. Never & 17 & 7.33 & - \\
\hline 2. Once a year or less & 7 & 3.02 & - \\
\hline 3. A few times a year & 105 & 45.26 & - \\
\hline 4. A few times a month & 51 & 21.98 & - \\
\hline 5. Once a week & 29 & 12.5 & - \\
\hline 6. More than once a week & 23 & 9.91 & - \\
\hline Total (n) & 232 & 100 & - \\
\hline \multicolumn{4}{|l|}{ NORA } \\
\hline 1. Never & 2 & 0.86 & - \\
\hline 2. Once a year or less & 6 & 2.59 & - \\
\hline 3. A few times a year & 11 & 4.74 & - \\
\hline 4. A few times a month & 23 & 9.91 & - \\
\hline 5. Once a week & 123 & 53.02 & - \\
\hline 6. More than once a week & 67 & 28.88 & - \\
\hline Total (n) & 232 & 100 & \\
\hline \multicolumn{4}{|l|}{ PRACTICE 1 (IR) } \\
\hline 1. Not at all & 0 & 0.00 & - \\
\hline 2. More towards not true & 2 & 0.86 & - \\
\hline 3. Not sure & 11 & 4.74 & - \\
\hline 4. More towards true & 12 & 5.17 & - \\
\hline 5. Very true & 207 & 89.22 & - \\
\hline$($ Mean $\pm S D)$ & \multicolumn{2}{|c|}{$4.83 \pm 0.54$} & $2 / 5$ \\
\hline
\end{tabular}

\section{PRACTICE 2 (IR)}

1. Not at all

2. More towards not true

\section{0}

2

0.00

3. Not sure

6

0.86

4. More towards true

13

5. Very true

211

2.59

5.6

90.95

$($ Mean \pm SD)

PRACTICE 3 (IR)

1. Not true at all

2. More towards not true

3. Not sure

4. More towards true

5. Very true (Mean \pm SD)

Total score (DUREL)

\section{0}

0 5 23 204
0.00

0.00

2.16

9.91

87.93

$4.86 \pm 0.41$

$23.09 \pm 2.52$

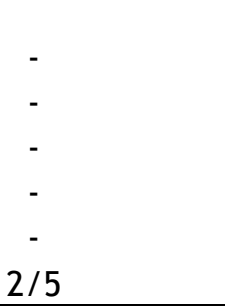

$2 / 5$

Note: ORA refers to organised religious activities that asks about the frequency of attendance at religious services and NORA is non-organised religious activities that asks regarding the frequency of private religious activities for the assessment of intrinsic religiosity; Intrinsic religiosity (IR) asks about experiencing the presence of God in our lives (Practice 1), Religious belief is with regards to the factors that lie behind our whole approach to life (Practice 2) and whether we carry our religious belief into all other dealings in life (Practice 3). 


\section{Religiosity}

The result shows that most women attending the Gynae Clinic in a Public Hospital have high beliefs in religion. Almost more than $93 \%$ of the respondents have gone to religious activities at the religious place while $99 \%$ of the respondents do religious activities alone at their convenience.

For Intrinsic Religiosity (IR), it shows that a majority of the respondents answered "very true" which proved that they believe in religion where the minimum answer was 2 and maximum was 5 . The average score for Practice 1, Practice 2 and Practice 3 were $4.83 \pm 0.54, \quad 4.87 \pm 0.47$ and $4.86 \pm 0.41$ respectively. See Table 4 .

\section{Depressive symptoms and socio-demographic data}

Table 5 shows the relationship between depressive symptoms and socio-demographic data. Only marital status was statistically significant with depressive symptoms $(p=0.012)$, where single women were having more depressive symptoms than married women. Other variables did not show any statistically significant differences with the groups of depressive symptoms $(p>0.05)$.

\section{Effects of menopausal symptoms and religiosity towards depressive symptoms}

Logistic regression was performed to examine the effects of menopausal symptoms and religiosity in the likelihood that respondents have depressive symptoms (Table 6). The model contained four independent variables (somatic, psychological, urogenital and religiosity). The full model containing all predictors was statistically significant, $x^{2} \quad(4, \quad N=232)=10.74, \quad p<0.05$, indicating that the model was able to distinguish between respondents who reported and did not report depressive symptoms. The model explained between 0.5\% (Cox and Snell R Square) and 0.7\% (Nagelkerke $\mathrm{R}$ Squared) of the variance of depressive symptoms, and correctly classified $80.2 \%$ of cases. As shown in Table 6, only urogenital was statistically significant to the model $(p=0.001)$, with an odds ratio of 1.765 . This indicated that respondents who had urogenital problems were 1.8 times more likely to report the depressive symptoms than those who did not have urogenital problems.

Table 5: Depressive symptoms and socio-demographic data $(n=232)$

\begin{tabular}{|c|c|c|c|c|}
\hline & $\begin{array}{c}\text { Absence of } \\
\text { depressive } \\
\text { symptoms } \\
(n=186)\end{array}$ & $\begin{array}{l}\text { Presence of } \\
\text { depressive } \\
\text { symptoms } \\
(n=46)\end{array}$ & Test Statistic & $\mathrm{p}$-value \\
\hline Age $^{a}($ mean $\pm S D)$ & $47.35 \pm 4.36$ & $47.17 \pm 4.00$ & & 0.206 \\
\hline Ethnicityc & & & 7.062 & 0.700 \\
\hline Malay & $172(80.4 \%)$ & $42(19.8 \%)$ & & \\
\hline Non-Malay & $14(77.8 \%)$ & $4(22.2 \%)$ & & \\
\hline Educational Level ${ }^{c}$ & & & 3.678 & 0.298 \\
\hline None & $15(88.2 \%)$ & $2(11.8 \%)$ & & \\
\hline Primary School & 48 (73.8\%) & $17(26.2 \%)$ & & \\
\hline Secondary School & $45(86.5 \%)$ & 7 (13.5\%) & & \\
\hline Tertiary Level & 78 (79.6\%) & $20(20.4 \%)$ & & \\
\hline \multicolumn{5}{|l|}{ Marital Status ${ }^{c}$} \\
\hline Unmarried & $3(42.9 \%)$ & $4(57.1 \%)$ & 6.322 & $0.012^{*}$ \\
\hline Married & $183(81.3 \%)$ & 42 (18.75\%) & & \\
\hline Occupation & & & 1.424 & 0.233 \\
\hline Unemployed & 57 (85.1\%) & $10(14.9 \%)$ & & \\
\hline Employed & 129 (78.2\%) & $36(21.8 \%)$ & & \\
\hline Household Income & & & 0.309 & 0.857 \\
\hline B40 (Below RM4360.00) & $51(80.9 \%)$ & $11(19.1 \%)$ & & \\
\hline M40(RM4361-RM9619.00) & 34 (73.9\%) & $12(26.1 \%)$ & & \\
\hline T20 (Above RM9620.00) & $92(80 \%)$ & $23(20.0 \%)$ & & \\
\hline Menstrual Status ${ }^{\mathbf{b}}$ & & & 0.992 & 0.055 \\
\hline Premenopausal & $113(85.6 \%)$ & 19 (14.4\%) & & \\
\hline Perimenopausal & 49 (72.1\%) & 19 (27.9\%) & & \\
\hline Postmenopausal & $24(75.0)$ & $8(25.0 \%)$ & & \\
\hline
\end{tabular}


Table 6: Logistic Regression Test $(n=232)$

\begin{tabular}{|c|c|c|c|c|c|c|c|c|}
\hline & \multirow[t]{2}{*}{ B } & \multirow[t]{2}{*}{ S.E } & \multirow[t]{2}{*}{ Wald } & \multirow[t]{2}{*}{ df } & \multirow[t]{2}{*}{$\mathrm{p}$} & \multirow[t]{2}{*}{$\begin{array}{l}\text { Odds } \\
\text { Ratio }\end{array}$} & \multicolumn{2}{|c|}{$\begin{array}{c}95 \% \text { Cl for Odds } \\
\text { Ratio }\end{array}$} \\
\hline & & & & & & & Lower & UppeI \\
\hline Somatic & -0.109 & 0.206 & 0.277 & 1 & 0.599 & 0.897 & 0.599 & 1.344 \\
\hline Psychological & 0.024 & 0.238 & 0.010 & 1 & 0.919 & 1.025 & 0.642 & 1.635 \\
\hline Urogenital & 0.568 & 0.177 & 10.321 & 1 & $0.001^{*}$ & 1.765 & 1.248 & 2.497 \\
\hline Religiosity & 0.021 & 0.070 & 0.088 & 1 & 0.766 & 1.021 & 0.891 & 1.170 \\
\hline Constant & -2.353 & 1.680 & 1.963 & & 0.161 & 0.095 & & \\
\hline
\end{tabular}

Note: ${ }^{*} \mathrm{p}<0.05$, statistically significant

\section{DISCUSSION}

\section{Socio-demographic data}

A total of 232 women aged 40 - 60 years old were recruited in this study. The average age of respondents in this study was 47 years, the lower age was 40 and the highest age was 59 years. This data is comparable to previous studies, which is around 48-49 years ${ }^{19}{ }^{20}{ }^{21}$. However, in other studies, their mean age was above the age of 50; for example, 58 years (since their sample was women aged from 45 to 86 years) $)^{5}, 57$ years ${ }^{22}$ and 51 years $^{6}$.

For ethnicity, the majority was Malay (92\%) and it was similar to a previous study ${ }^{5}$. This study was done in an area where a majority of the residents are Malays although they came from three different districts (Gombak, Petaling and Kuala Selangor). In this study, respondents were categorised as married $(97 \%)$, even though they have already divorced or separated. However, in a study done by Hongyan et al. ${ }^{23}$, divorced and widowed women were categorised as "single".

Educational level in this study was classified according to the educational level in Malaysia in view of the current situation. Nearly half of the respondents graduated at tertiary level (42.2\%). Furthermore, the results from this study showed that a majority of them were employed $(71 \%)$ and $50 \%$ of the respondents fall under the category of T20. It can be stated that a majority of the women attending the clinic were of a higher household income. The median income for the respondents in this study was RM5197 and was concurrent with the latest median monthly household income which is RM5228 in $2016^{24}$.

\section{Menopausal Symptoms}

In general, the most frequently reported menopausal symptoms tend to be in the somatic subscale; joint muscle discomfort, sleeping problems, and hot flushes. According to Ketch et al. ${ }^{25}$, somatic symptoms can happen at any time in life, but most often begins in early adulthood. This study findings were quite similar with another study, that reported a higher incidence of physical symptoms $(91.5 \%)$, followed by psychosocial $(44.7 \%)$, vasomotor $(21.3 \%)$, and sexual $(0 \%)^{19}$. In this study, the frequency of hot flushes (50.4\%) was found to be lower compared to other local studies $^{5}{ }^{6}$. Nevertheless, there is a study that showed only $40 \%$ reported the symptoms ${ }^{22}$, however, the results might not be generalised as the sample also included women with hormone replacement therapy. A study conducted in Saudi Arabia suggested hot flushes may be attributable to the exceptionally hot local climate, which decreases the vulnerability of women to elevated temperatures, or alternatively, women may attribute the warming sensation of hot flushes to ambient weather ${ }^{20}$.

For psychological symptoms, the result shows that the highest percentage reported was lethargic symptoms, but the score was around mild to moderate, which was similar to a study conducted in Egypt ${ }^{26}$. Likewise, a study done among Turkish women stated that the percentage of women with this symptom was $21.9 \% 27$. A study conducted in India found that only $6 \%$ of postmenopausal women had depression ${ }^{28}$, while another study found that, this symptom was higher in the postmenopausal group ${ }^{20}$. The psychological symptoms were reported to be very high $(90.7 \%)$ among women in Kerala, India ${ }^{29}$, but it could be due to the wide-range of the women's age in their study sample (32 to 82 years).

\section{Depressive Symptoms}

Depressive symptoms are common in all populations but tend to be higher during the transition to menopause among women ${ }^{3}$. According to Ellen ${ }^{3}$, there is evidence to support the role of the evolving endocrine environment in developing the depressive mood during menopause transition, but the hormone contribution is considered small. This study has shown that almost $80 \%$ of the respondents did not have serious depressive symptoms. However, there were $20 \%$ of the respondents that needed extra care due to subthreshold depression symptoms. Also, in the MRS, under the psychological subscale, only $3 \%$ of the respondents reported having severe symptoms of depression. This study shows similarities with previous studies conducted where the percentage of the CESD scores of 16 and above were around $23-24 \%{ }^{3}{ }^{30}$. A previous study done in 2016 found that depressive symptoms among respondents was $11.4 \% 23$. It was reported that depressive symptoms among women were not merely linked to menopause per se, but could possibly be due to other conditions ${ }^{3}$. 


\section{Religiosity}

Most of the women attending the Gynae Clinic in a Public Hospital have high beliefs in religion. Although there were some respondents who reported low frequency of attending the house of worship (such as mosques, temples or churches), this cannot be considered significant because all of the respondents were women, and in this study the majority of respondents were Malays (Muslim). In the Islamic religion, the presence of women in the house of worship such as mosques or surau is not an obligation of their beliefs as narrated by Ibn Umar Radiallahu Ánhu who said : The Prophet S.W.T said: Do not prevent your woman from going to mosques. But their homes are better for them (Sunan Abu Daud, Kitab as Solat, Bab Ma Jaa Fi Khuruj an-Nisa'llal al-Masjid, hadis no 479, Sahih Lighairih).

A previous study done in 2010 found that only $20.9 \%$ of the respondents attended church or other religious meetings, whereas $46 \%$ spent time in private religious activities ${ }^{12}$. However, this study was done in a Western country and most of them were non-Muslims. In a local study conducted by Nurasikin et al. ${ }^{18}$ it was found that those who were committed to religion used a more positive religious coping pattern.

\section{Depressive symptoms and socio-demographic data}

The data for the relationship between depressive symptoms and demographics indicated that there was a relationship between marital status and depressive symptoms, where depressive symptoms were prevalent among unmarried women.

It was stated that marital status showed a significant result in relation to depression symptoms among women ${ }^{3}$. Marital status was related with the occurrence of major depression; however, the strength of the relationship was modified by age $^{31}$. Furthermore, a study found that the depressive rates were lower for those who were single, widowed or divorced compared to those who were married ${ }^{28}$. In contrast, other studies found that there were no significant differences between married women and those who were widowed, divorced or separated with depressive symptoms 3233 .

\section{Menopausal, religiosity and depressive symptoms}

In this study, the results showed that only urogenital problems affect the depressive symptoms. Menopausal women with urogenital problems were 1.8 timesmore likely to develop depressive symptoms. This is similar to a previous study, which stated that urinary incontinence was related with developing depressive and anxiety symptoms $^{34}$. A study done among menopausal women in Iran mentioned that depression and sexual dysfunction were correlated ${ }^{35}$. Menopausal period occurs mostly among the senior citizens, and those urogenital symptoms will influence their mood, sexuality and emotional well-being during the ageing process. It is hoped that in the future, a special therapeutic assessment and intervention for menopausal women can be provided in order to reduce urogenital symptoms and thus prevent the development of depression.

\section{CONCLUSION}

In conclusion, most of the respondents reported joint and muscle discomfort and sleeping problems as symptoms of menopause. Yet, they have good religiosity, in terms of belief and practice. The results also showed that the prevalence of depressive symptoms was relatively low, and single women were more depressed than married women. There was also an association between urogenital problems and depressive symptoms among menopausal women.

Although the percentage of depressive symptoms in this study was small, the potential of this population to have depression cannot be ignored. The government needs to establish a dedicated facility or service especially for those with urogenital and depressive symptoms. Special attention and screening for depressive symptoms need to be given to single menopausal women and women who developed urogenital problems. Premenopause clinic programs are suggested to be provided in existing health facilities to encourage women to get early care advice when appropriate.

\section{ACKNOWLEDGEMENT}

Our appreciation goes to the Centre for the Nursing Studies, Faculty of Health Sciences, and the Research Ethic Committee, Universiti Teknologi MARA and the Obstetrics and Gynaecologyas well as the Psychiatric Department in Sungai Buloh Hospital and lastly, the Ministry of Health. Thank You.

\section{Conflict of Interest None}

\section{REFERENCES}

1. World Health Organization. Research on the Menopause in the 1990 (WHO Technical Report, Series No 866) Geneva 1996

2. Davis SR, Lambrinoudaki L, Lumsden $M$, Menopause Nat Rev Dis Primers 2015; 1(1)

3. Ellen WF, Depression in the menopause transition: risks in the changing hormone milieu as observed in the general population Freeman Women's Midlife Health 2015;1:2

4. Placido L, Maria P, Garcia P, David LS, Begona A, Depressive disorders and the 
menopause transition Maturitas 2012; $71: 120-13$

5. Bahiyah A, Burhonuddin M, Badrul Al, Madihah Z, Najihah MN, Prevalence of menopausal symptoms, its effect on quality of life among Malaysian women and their treatment seeking behavior. Medical Journal Malaysia, 2017; 72(2), 9499

6. Rahman SASA, Zainudin SR, Mun VLK, Assessment of menopausal symptoms using modified Menopause Rating Scale (MRS) among middle age women in Kuching, Sarawak, Malaysia. Asia Pacific Family Medicine, 2010; 9(1), 5. https://doi.org/10.1186/1447-056X-9-5

7. Rajbhandari S, Subedi R, Dangal G, Phuyal A, Vaidya A, Karki A, Tuladhar H, Gurung B, Joshi L, Shrestha S, Menopausal Health States of Nepalese Women Journal of the Nepal Medical Association, 2017; 56(205).

8. North American Menopause Studies. The 2012 Hormone Therapy Position Statement of The North American Menopause Society HHS Public Access, 2012; 19(3);257-271

9. Vesco KK, Haney EM, Humphrey L, Fu R, Nelson HD, Influence of menopause on mood: a systematic review of cohort studies Climacteric, 2007; 10(6);448-465 https: / /doi.org/10.1080/1369701611267

10. Firdaus M, Tian PSO, A Review on the Prevelance of Depression in Malaysia Current Psychiatry Review. 2011; 7 (000000)

11. Koenig HG, Religion, Sprituality, and Health: The Research and Clinical Implications International Scholarly Rresearch Network ISRN Psychiatry, 2012; https: / / doi/org/10.50402/2012/278730

12. Koenig HG, Arndt B, The Duke University Religion Index (DUREL): A Five Item Measure for Use in Epidemiological Studies Religions (Open Access), 2010; (1) 78-85

13. Shanshan L, Olivia IO, Shun CC, Tyler J, Religious service attendance and lower depression among women - a prospective cohort study HHS Public Access, 2016; $50(6)$

876-884

http: //doi.org/10.1007/s12160-0169813-9

14. Raosoft.com. Sample Size Calculation Calculator

2004 http://www.raosoft.com/samplesize.ht $\mathrm{ml}$

15. Rahman SASA, Zainudin SR, Mun VLK, Assessment of menopausal symptoms using modified Menopause Rating Scale (MRS) among middle age women in Kuching, Sarawak, Malaysia. Asia Pacific Family Medicine, 2010; 9(1), 5. https: / /doi.org/10.1186/1447-056X-9-5

16. Heinemann $L A J$, DoMinh $T$, Strehlow $F$, Gerbsch S, Schnitker J, Schneider, HPG. Validity of the Menopause Rating Scale as outcome measure. A clinical outcome study, 2004; 2(45) www.hqlo.com/content/2/1/67

17. Eaton WW, Smith C, Ybarra M, Muntaner C, Tien A, Center for Epidemiologic Studies Depression Scale: Review and revision (CESD and CESD-R). In M. E. Maruish (Ed.), The use of psychological testing for treatment planning and outcomes assessment: Instruments for adults, 2004; 363-377. Mahwah: Lawrence Erlbaum

18. Nurasikin MS, Aini A, Aida Syarinaz AA, Ng CG, Validity and Reliability of the Malay Version of Duke University Religion Index (DUREL-M) Among A Group of Nursing Student. Malaysian Journal of Psychiatry, 2010; 19 (2)

19. Shukla R, Ganjiwale J, Patel R, Prevalence of Postmenopausal Symptoms, Its Effect on Quality of Life and Coping in Rural Couple. Journal of Midlife Health, 2018; 9 (1) $14-20$

20. Aida A, Hind A, Mohammed A, Menopausal Symptoms and quality of life among Saudi women visiting primary care clinics in Riyadh, Saudi Arabia International Journal of Women's Health, 2015;7 645-653

21. Kamal NN, Seedhom AE, Quality of life among postmenopausal women in rural Minia, Egypt Eastern Mediterranean Health Journal, 2017; 23(8)

22. Matthew $S$, Jeffry $T$, Craig B, Sebastian $M$, Andrew G, Bushmakin, Robert Y, Mark F, Joseph M, Michael L, Prevalence of menopausal symptoms among mid-life women: findings from electronic medical records. BMC Women's Health, 2015; 15(58)

23. Hongyan Z, Lianping $\mathrm{H}$, Yan $\mathrm{C}$, Jianfeng g, Yingshui $Y$, The association of depression status with menopause symptoms among rural midlife women in China African 
Health Science, 2016; 16(1): 97-104

24. Department of Statistic Malaysia, Population in Malaysia, 2019; http://www.dosm.gov.my

25. Ketch C, Weedin E, Gibson BA, Management of the symptoms of Perimenopause 2017; In: Shoup D. (eds) Handbook of Gynaecology, Springer, Cham.

26. Kamal NN, Seedhom AE, Quality of life among postmenopausal women in rural Minia, Egypt Eastern Mediterranean Health Journal, 2017; 23(8)

27. Hatice KS, Needet S, Severity of Menopausal Symptoms in Climacteric Turkish Women International Journal of Caring Sciences, 2017; 10(1):383.

28. Leena AJ, Acka PV, Prevalence of menopausal symptoms nd perceptions about menopause among postmenopausal women attending Gynaecology OPD at GMC Idukki, India International Journal of Reproduction, Contraception, Obstetrics and Gynaecology, 2017; 6(2): 413-416

29. Sagar $A B$, Venugopalan PP, Shruthi N, Study of menopausal symptoms, and perceptions about menopause among women at a rural community in Kerala Journal of mid-life health 2013; 4(3): 182

30. Jessica PB, Lisa G, Jodi FF, Tracy KJ, Relations among Menopausal Symptoms, Sleep Disturbance and Depressive Symptoms in Midlife National Institutes of Health, 2009; 62(2):184-189 http://doi.org/10.1016/j.maturitas.2008 .11 .019

31. Bulloch AGM, Williams JVA, Lavorato DH, Pattern SB, The Depression and marital status relationship is modified by both age and gender. J Affect Disord, 2017; 223:6568

https://doi.org/10.1016/j.jad.2017.06.0 07.

32. Soong $\mathrm{NJ}$, Ichiro $\mathrm{K}$, Jiyeun $\mathrm{C}$, Kachung $\mathrm{B}$, Hyun GS, Hyejung L, Sung C, Marital Status, Gender, and Depression: Analysis of the Baseline Survey of the Korean Longitudinal Study of Ageing (KLoSA) Soc Sci Med, 2009; 69 (11):1608-1615

33. St John PD, Montogomery PR, Marital status, partner satisfaction, and depressive symptoms in older men and women Can. J Psychiatric, 2009; 54(7):487-492
34. Felde G, Ebbesen $\mathrm{MH}$, Hunskaar S, Anxiety and depression associated with urinary incontinence. A 10-year follow-up study from the Norwegian HUNT study (EPINCONT), Neurology and Urodynamics, 2017; 36:322-328

35. Yazdanpanahi Z, Nikkholgh M, Akbarzadeh M. Pourahmad S, Stress, anxiety, depression, and sexual dysfunction among postmenopausal women in Shiraz, Iran, J Family Community Med, 2018; 25(2): 82-87. 